\title{
NEOCLASICISMO, CEMENTERIOS E ILUSTRACIÓN EN CUBA EN LAS PRIMERAS DÉCADAS DEL SIGLO XIX
}

\author{
Neoclassicism, cementeries and Enlightenment in Cuba in the first decades of the 19th century
}

\author{
Martha Elizabeth LAGUNA ENRIQUE \\ Universidad de Salamanca \\ E-mail: lagunaenrique@usal.es
}

Fecha de recepción: $20-01-2010$

Fecha de aceptación: 29-01-2010

RESUMEN: La historia de la arquitectura funeraria en La Habana, comenzó con la construcción del Cementerio General (1806), auspiciado por el obispo vasco Juan José Díaz de Espada, primer campo santo que se construyó en Hispanoamérica, como consecuencia de la Real Cédula de Carlos III, fechada el tres de abril de 1787, que obligó a todos los ayuntamientos a erigir necrópolis municipales en lugares apartados de los núcleos urbanos y que acabó con la costumbre de enterrar en las iglesias y conventos.

Ese recinto funerario inicial, ya desaparecido, fue realizado por el arquitecto francés Étienne-Sulpice Hallet, figura poco estudiada en el contexto cubano y que introdujo el neoclasicismo dentro de la arquitectura habanera. La presente comunicación plantea un acercamiento al tema del desarrollo de las ideas ilustradas en Cuba y la difusión del neoclasicismo como estilo dominante en la arquitectura funeraria de la isla, durante las primeras décadas del siglo XIX.

Palabras Clave: Neoclasicismo, Ilustración, obispo Espada, Cementerio General, arquitectura, La Habana.

ABSTRACT: The history of funerary architecture in La Habana begin with the construction of the Cementerio General (1806), promoted by the basque bishop Juan José Díaz de Espada, first graveyard built in Hispanoamérica, after the Real Cédula of Carlos III dated on the third of April of 1787. For their contents, all municipalities must to construct mu- 
nicipal graveyards in remote sides from the urban areas and ended with the tradition of burying in churches and convents.

This initial funerary area, today disappeared, was built by French architect ÉtienneSulpice Hallet, figure barely studied in the Cuban context. He introduced the neoclassicism in the Cuban architecture. This communication presents an introduction of the development of illustrate ideas in Cuba and the diffusion of the neoclassicism as dominant style in the funerary architecture of the island, during the firsts decades of XIX century.

Keywords: Neoclassicism, Enlightenment, Bishop Espada, General Cemetery, Architecture, La Habana

\section{ILUSTRACIÓN Y PROGRESO EN CUBA.}

Frente a las tendencias minimizadoras que pretendieron devaluar la dimensión histórica de la Ilustración hispana, se levanta la fuerza y originalidad de un movimiento intelectual e ideológico que comenzó con la llegada de los Borbones al trono en el siglo XVIII e introdujo notables avances en la educación, las ciencias y las obras públicas. Las luces del pensamiento y la razón invadieron tanto la política como la vida en general. Así, la instauración de la dinastía borbónica en la península trajo aparejadas indiscutibles transformaciones estéticas, sociales e intelectuales que desembocaron en el auge de un nuevo estilo artístico: el neoclasicismo.

En el caso específico de Cuba, a partir de 1763, con la devolución de La Habana por parte de los ingleses al dominio español, la asimilación de la Ilustración por los criollos y la puesta en marcha de reformas basadas en las ideas ilustradas de la época resultan significativas. Ciertamente, pueden distinguirse dos períodos dentro de lo que se ha denominado por los historiadores y estudiosos del tema como Ilustración reformista cubana. En un primer momento, se impulsaron una serie de cambios económicos y administrativos, unidos al auge de la plantación esclavista y al sentimiento de los criollos que, con liderazgo propio, estimularon patrones económicos relativamente nuevos para el desarrollo interno de la isla. Como ya nos ha explicado Hugh Thomas: Durante la segunda mitad del siglo XVIII, Cuba se transformó en una próspera colonia azucarera debido a cuatro causas principales. En primer lugar, influyó la creación de nuevos mercados para el azúcar, tanto en España como en otros puntos, incluyendo los recientemente independizados Estados Unidos de América; en segundo lugar, la emergencia de una clase de propietarios más interesados en el desarrollo de sus tierras y en promover riqueza que en preservar su estatus; en tercer lugar, la importación de esclavos, en una escala mucho mayor que antes desde Africa; y finalmente, una serie de reformas económicas de gran alcance introducidas por los ministros ilustrados del rey Carlos III, así como la desaparición de varias de las viejas restricciones que pesaban sobre el comercio ${ }^{1}$. El año 1802 marcó el comienzo de un nuevo período, con la irrupción 
de un movimiento intelectual que se orientó a la esfera social y al pensamiento mucho más que a la economía. Su figura aglutinadora fue el obispo vasco Juan José Díaz de Espada y los dos centros de proyección fundamentales estaban situados en el Real Seminario de San Carlos y San Ambrosio y en la Sociedad Patriótica de Amigos del País de La Habana².

Vieron la luz así, importantes manifestaciones científicas, culturales y filosóficas, es decir, un movimiento intelectual que legó personalidades indiscutibles a la historia de la nación cubana. Francisco de Arango y Parreño en la economía, José Agustín Caballero en la filosofía y Tomás Romay Chacón en la medicina, junto a discípulos y seguidores ilustres como Félix Varela y Morales, José Antonio Saco, Felipe Poey, entre otros, son sólo algunos ejemplos que demuestran la fuerza del movimiento ilustrado en Cuba.

Como podemos apreciar, los cambios que se implantaron en la isla caribeña a través de las reformas ilustradas, se extendieron más allá de los circuitos eclesiásticos, la política y la economía, para abarcar la educación, la salud pública e incluso la esfera artística. En este sentido, el establecimiento del Cementerio General en extramuros significó un avance importante en la higienización de la ciudad, pero también representó la aparición de una nueva tipología arquitectónica: la funeraria, que trajo consigo la irrupción de un nuevo estilo artístico en el contexto cubano: el neoclasicismo.

\section{Un CEMENTERIO NEOCLÁSICO PARA LA HABANA.}

En los primeros años del siglo XIX, el mencionado obispo Juan José Díaz de Espada, quien estuvo al frente del Obispado de San Cristóbal de La Habana entre 1802 y 1832, con el apoyo del capitán general y gobernador Salvador de Muro y Salazar, marqués de Someruelos ${ }^{3}$, la Sociedad Patriótica de Amigos del País de La Habana, las parroquias de la Diócesis y el médico Tomás Romay Chacón, logró dos medidas sanitarias fundamentales: la prohibición de los enterramientos en la iglesias y conventos con la creación del Cementerio General y la extensión del uso de la vacunación.

Al hacerse cargo de la mitra el veintiocho de febrero de 1802, el obispo Espada se convirtió en puntal de la lucha por eliminar la antihigiénica costumbre de enterrar en las iglesias, hondamente arraigada en la población, pero insostenible ya a principios del siglo XIX por la falta de espacio de las edificaciones religiosas donde se inhumaba. La cuestión de los enterramientos era, por esas fechas, monopolio exclusivo de la Iglesia que controlaba las sustanciosas ganancias obtenidas por ese concepto. Pese a todo, el obstáculo fundamental a franquear para el establecimiento de la necrópolis en extramuros fue de índole económico. 
La construcción del campo santo habanero, que pasaría a la historia con el nombre de Cementerio de Espada, en justo homenaje a su obispo fundador, se prolongó durante dos años (1804-1806). Su localización se planteó a una distancia aproximada de una milla al oeste del recinto amurallado de La Habana, limitando por el noreste con el pequeño cementerio provisional del hospital de San Juan de Dios ${ }^{4}$, donde se construiría más tarde, en 1828, la Casa de dementes de San Dionisio ${ }^{5}$; a continuación del cual se encontraba establecido el Hospital de San Lázaro ${ }^{6}$. Así las cosas, el perímetro del cementerio lo dibujaban las calles Aramburu, San Francisco, San Lázaro y Vapor, en el actual municipio capitalino de Centro Habana ${ }^{7}$ (Fig. I). Muy cerca de allí, en la manzana rodeada de las actuales calles 25, Hospital, Espada y Príncipe, estaban las antiguas canteras de San Lázaro, donde los presos eran obligados a realizar trabajos forzados ${ }^{8}$.

Los planos del cementerio, la portada principal, la capilla, los edificios de servicio anexos y la forma de ejecución fueron propuestos por el arquitecto francés de gusto neoclásico Etienne-Sulpice Hallet. Lamentablemente estos dibujos no han podido localizarse en los archivos y en la bibliografía consultada no existe ninguna referencia que aporte luces en este sentido, por lo que es bastante probable que no se conserven los originales.

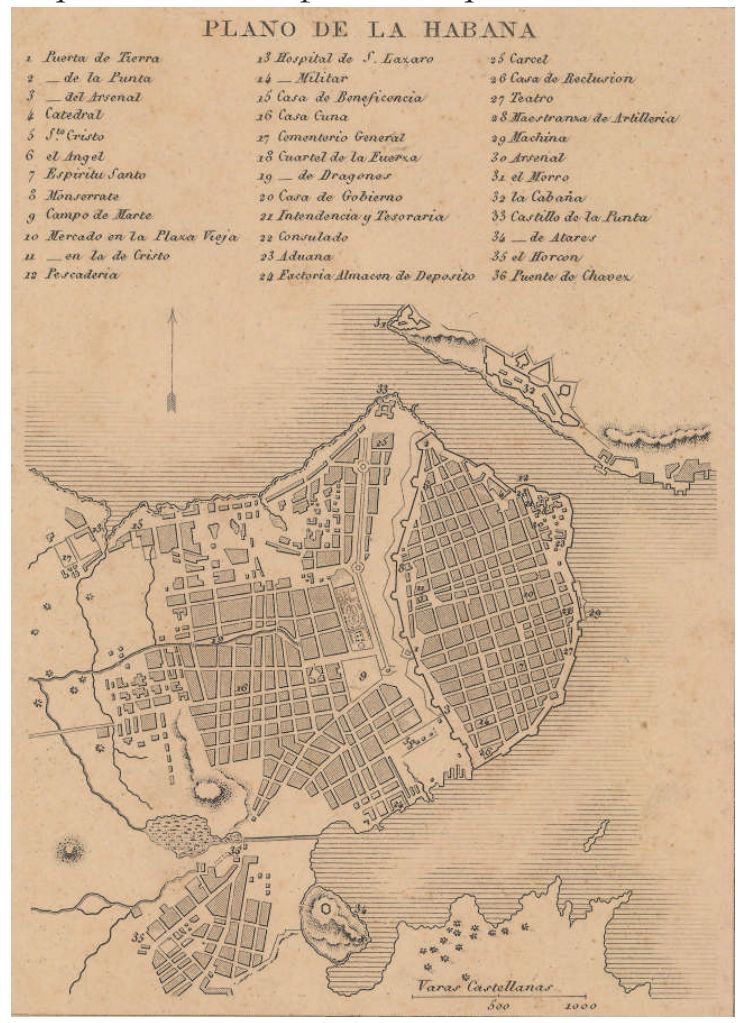

Fig. I. Plano de La Habana, 1850. Francisco Coello.

Instituto Cartográfico de Cataluña, Barcelona. 
La ejecución del proyecto también estuvo a cargo de este arquitecto, radicado en los Estados Unidos desde 1789, donde se dio a conocer como Stephen Hallet, aunque a menudo su nombre ha sido transcrito como Allet. Según las investigaciones realizadas, este arquitecto había participado en el concurso para la construcción del Capitolio de Washington en 1793, en el que su diseño quedó en segundo lugar detrás del proyecto propuesto por el arquitecto William Thornton que, se plantea, fue aprobado y corregido por el propio presidente George Washington. Se dice que Étienne-Sulpice Hallet supervisó los trabajos del Capitolio entre los años 1793 y 1794, momento en el que surgieron diferencias, por lo que abandonó la construcción del edificio?.

La figura de Étienne-Sulpice Hallet se pierde dentro de la bibliografía de arquitectura cubana del siglo XIX. Su efímero periplo por la isla no ha sido suficientemente abordado, quizás en parte porque las dos construcciones en las que participó no se conservan en la actualidad. La mayoría de los textos que hacen referencia al Cementerio General no le mencionan siquiera, incluso, en muchas ocasiones, como hemos podido comprobar, se trueca su apellido.

Todo parece indicar que el experimentado arquitecto se trasladó a La Habana alrededor de 1800, para asumir poco después la reconstrucción total del otrora Coliseo de las comedias, más tarde conocido como Teatro Principal, que reabrió sus puertas en $1803^{10}$. Esa obra se levantó al pie de la calle de los Oficios, frente a la Alameda de Paula, y era uno de los teatros más conocidos de la época colonial, con una fachada de diseño francés, es decir neoclásico y una distribución muy similar a la del Teatro Principal de Madrid.

Joaquín E. Weiss, en su clásico Arquitectura colonial cubana. Siglos XVI al $X I X$, decía no tener certeza de que se tratara del arquitecto francés del Capitolio norteamericano ${ }^{11}$. Sin embargo, Narciso García Menocal, profesor de la Universidad de Wisconsin, en Madison, en un artículo más reciente, que redefine la figura de Hallet y su recorrido profesional, refiere la presencia del arquitecto francés en La Habana, por esos años ${ }^{12}$. Queda constancia de ello también en la prensa de la época, ya que el Papel Periódico, del nueve de febrero de 1804, anunció una función en beneficio de Hallet, arquitecto y director de la fábrica del Coliseo ${ }^{13}$. En 1804 le sería adjudicada la construcción del Cementerio General de La Habana, ejerciendo además como contratista en esta obra funeraria, que como se verá más adelante introdujo de forma fehaciente el neoclasicismo dentro de la arquitectura habanera ${ }^{14}$.

Para la construcción se adoptó la tipología de cementerio porticado ${ }^{15}$, al aire libre, de acceso más o menos monumental, con capilla al fondo del recinto. (Fig. II). Correspondía a un tipo de trazado muy habitual en la época, que de hecho se extendió por diversos lugares de España, sobre todo en las 
grandes poblaciones, y tuvo un apreciable arraigo en distintas zonas del País Vasco, donde ese fruto de la Ilustración adquirió particular relevancia ${ }^{16}$.

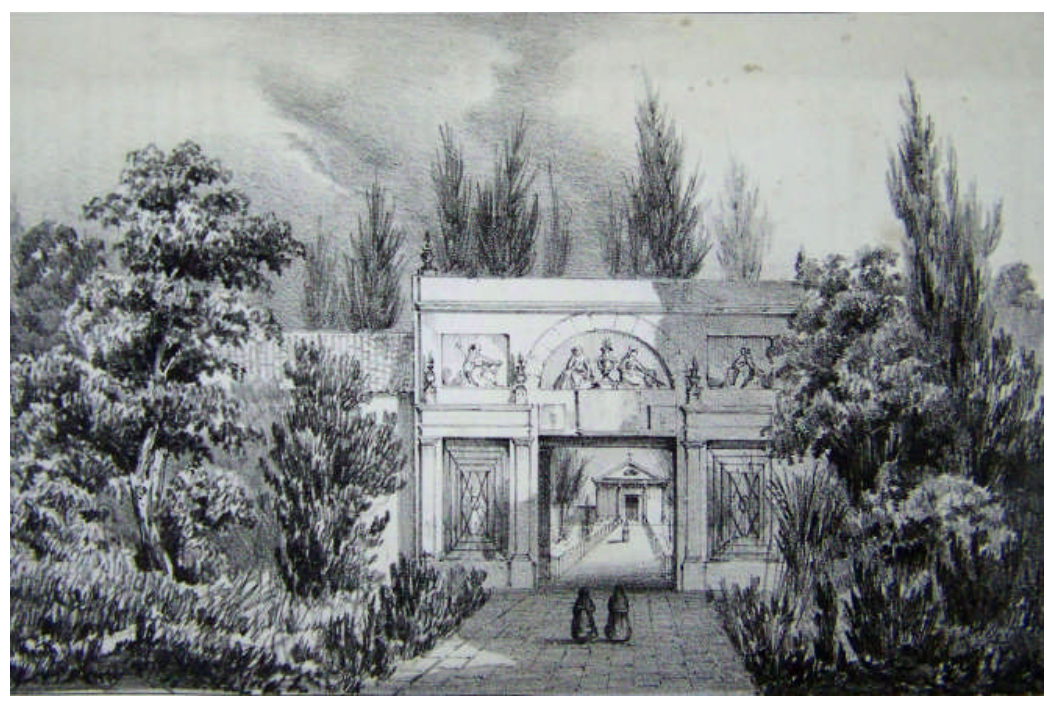

Fig. II. Entrada del Cementerio General de La Habana.

Litografía, Mialhe, F.: En El Plantel (La Habana). Vol. I (1828), pág. 228.

Con toda certeza el obispo Espada tenía información detallada en materia de cementerios y probablemente propuso basar el diseño del campo santo habanero en el modelo de planta y alzado que proponía la Real Cédula de Carlos III, es decir el Cementerio del Real Sitio de la Granja de San Ildefonso (Segovia), inaugurado el ocho de julio de 1785. Así, el antecedente neoclásico del recinto habanero podría haber sido este cementerio modelo, uno de los primeros que se construyeron en España, o cualquier otro similar. La planta rectangular, la capilla frente a la puerta de entrada, las formas geométricas simples y la portada de ingreso rematada en frontón triangular -que en el caso habanero se transmuta en ático con inscripciones-, fueron elementos recurrentes y característicos de la tipología funeraria durante estos años.

Dos estructuras del recinto funerario sobresalían como las de mayor importancia: la portada de ingreso y la capilla ${ }^{17}$, La primera de unos 41,80 metros de ancho, era la más trabajada artísticamente. Concebida como límite entre el espacio sacro y el profano, como división entre el mundo de los vivos y el mundo de los muertos, se distinguía por su acentuada severidad y por el predominio en la misma del macizo sobre el vano, cuando menos la paridad entre ambos. Todos los huecos del recinto estaban protegidos por rejas y 
cumpliendo aquella disposición establecida por la Real Cédula de Carlos III, en la que se indicaba la necesidad lógica de acotar el terreno con una verja más o menos artística, para la protección del recinto sagrado. Además, la portada estaba articulada en dos cuerpos y tres calles, de las que la central acogía el acceso, que era adintelado y estaba delimitado por dos pilastras con capiteles toscanos. Otros dos huecos, también adintelados, protegidos por rejas con barrotes de sección cuadrada, adornadas por antorchas de bronce, presidían los extremos.

El cuerpo alto estaba diseñado a modo de ático, decorado por relieves que representaban el Tiempo y la Eternidad en las calles extremas, mientras que sobre el ingreso, aparte de la cartela en la que se leía la inscripción $A$ la religión. A la salud pública-Año 1865. El marqués de Someruelos, Gobernador. Juan de Espada Obispo, había un ánfora, vaso típicamente clásico, cuya simbología alude al paso fugaz por la vida y el poder destructivo del tiempo, que todo lo transforma en humo. El atrio terminaba con dos macetas realizadas en piedra de las canteras de San Miguel, colocadas en los extremos. A ambos lados de la portada se pintaron dos imágenes enmarcadas entre las pilastras: la Medicina -en la izquierda- y la Religión -a la derecha-. Adentrándonos en el recinto encontrábamos la vivienda de los sepultureros, a la izquierda y la del capellán al lado derecho ${ }^{18}$.

Resulta oportuno anotar además que éste era un cementerio mixto de inhumación y de nichos. Los nichos que como sabemos, constituyen un sistema de enterramiento más económico, se construyeron en 1845 en sustitución de las sepulturas para los enterramientos y resultaban muy acertados en este caso, pues duplicaban o triplicaban la capacidad inhumatoria del recinto funerario $^{19}$ (Fig. III).

El Cementerio de Espada, de aspecto decoroso, aunque un tanto modesto, estuvo cercado por una pared de mampostería mixta con caballete de sillería labrada. Por lo demás, la necrópolis se ajustó a la tradición de colocar cinco cruces, una en el centro y otras cuatro en cada uno de los ángulos. En este caso la primera se ubicó al norte -capilla-, mientras que en los vértices se instalaron obeliscos de un material que imitaba el jaspe negro. Bajo estos últimos, en cuyos muros se leía la inscripción bíblica Exultabunt osa bumiliate (Se regocijarán los huesos humillados) estaban los osarios, construidos a modo de pozos, en los que se depositaban los huesos una vez exhumados los cadáveres. 


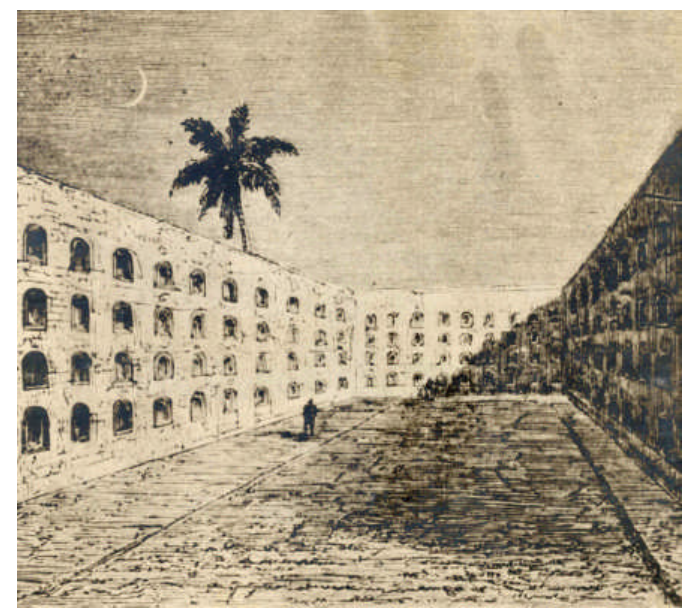

Fig. III. Nichos del Cementerio General de La Habana.

Archivo Histórico Nacional de Cuba, Fototeca.

La capilla del cementerio, situada, como hemos visto, al lado norte, tenía planta rectangular, una rigurosa simetría, vanos en los costados, cubierta a doble vertiente y estaba precedida por un pórtico de cuatro columnas exentas, que sostenían un frontón triangular, en el que se leía en letras de bronce una frase en latín. Sobre este particular, existen discrepancias en las fuentes consultadas, porque, según afirmó el periodista y escritor romántico español, José María de Andueza (Aben-Zaide era su seudónimo), la inscripción rezaba Ecce nune in pulveri dormiam-Job $V T^{20}$ y debajo Et ego resucitado cum in novísimo dieJuan $V I^{21}$. Esto no coincide con lo indicado por Francisco Xavier de Santa Cruz y Mallén, conde San Juan de Jaruco, que colocó en el mismo lugar el conocido versículo del Apocalipsis Beati mortiu qui in Domino moriuntur: opera inimolorum seuuntier illos apoc ${ }^{22}$. No obstante, ambos afirmaron que este conjunto estaba rematado por una cruz de piedra caliza, del tipo de cruz trebolada, con decoraciones circulares en su interior, pintada de color ocre rojizo con manchas negras ${ }^{23}$. Durante años fue esta la única cruz que existió allí, porque el obispo Espada había prohibido el uso decorativo de las cruces en las sepulturas privadas.

En referencia a la capilla se ha dicho que tenía (...) un sello peculiar de templo antiguo ${ }^{24}$ y que era sencilla y de buen gusto ${ }^{25}$. En otro lugar fue definida como una pequeña y pulcra capilla que contenía unas pocas pinturas al fresco y un casto altar en forma de sarcófago ${ }^{26}$. Lo cierto es que, por la imagen que sugieren las escasas descripciones que existen de este lugar, era un severo templo ubicado al fondo de la avenida principal del recinto funerario, en cuyo exterior llamaba la atención la austeridad, dada la contenida ornamentación reducida a los volúmenes esenciales. 
Las inclinaciones artísticas del obispo se pusieron de manifiesto también en la decoración interior de la capilla. Así en la cabecera destacaba un fresco del Juicio Final, sobre el que revoloteaba un ángel con una trompeta de la cual partía la inscripción latina Surgite mortui et venite at judicimn $n^{27}$. Todo ello era obra del célebre pintor neoclásico José Perovani Rústica, formado en Roma, que residió algún tiempo en Filadelfia y que fue contratado para la realización de los trabajos pictóricos de la capilla por el propio obispo. Llegados a este punto, resulta oportuno señalar que este prelado realizó otras acciones que confirman su explícita predilección por el estilo neoclásico al sustituir por razones estéticas, las pinturas y los altares barrocos de la Catedral de La Habana por otros puramente neoclásicos, reforma irreversible y polémica, que suscitó amplias críticas en su época.

Resulta evidente que esta necrópolis correspondía a una arquitectura sensible al espíritu del Siglo de las Luces, que reaccionaba contra las soluciones estéticas imperantes hasta poco antes en Cuba, valiéndose de recursos que se apartaban con su impulso renovador de la exuberancia del barroco, prefiriendo recuperar las huellas de la Antigüedad clásica. La simetría, el equilibrio de la portada principal, la sobriedad del diseño, etc., evidencian los referentes neoclásicos del recinto funerario habanero, resultando así un ejemplo temprano de este movimiento estético en la arquitectura de la capital cubana del siglo XIX, quizás no tan consecuentemente neoclásico como lo sería años después El Templete $(1828)^{28}$, construcción en la que también el obispo Espada jugó un papel determinante.

Daba inicio así, un período neoclásico dentro de la arquitectura cubana del siglo XIX que también tendría incidencia en los palacios y casas privadas de la época, ejemplos indispensables para entender la evolución de este estilo en Cuba y sus diversas variantes ${ }^{29}$. El hecho de que Espada contratara a un arquitecto como Étienne-Sulpice Hallet, que poco antes había realizado una obra de diseño eminentemente francés en la ciudad, refuerza la idea de su indudable preferencia por ese movimiento artístico.

El Cementerio de Espada fue demolido en 1908. Luego el terreno fue vendido y sobre ese espacio se levantaron nuevas construcciones, sobre todo viviendas familiares. La transcendencia de esta obra pública, paradigma dentro de la historia de esta tipología arquitectónica en Cuba y en Latinoamérica, al ser el primer cementerio municipal construido en la América hispana, proyectado por un arquitecto a la manera de los más sobresalientes ejemplos europeos de la época, queda expresada en el patético canto que el poeta Manuel de Zequeira y Arango le dedicara: 
Desciende, Musa de la cumbre y canta

Con nuevo sistro y con canoro aliento

Elpúblico Panteón, el monumento

Que á la salud levanta,

$Y$ á la Religión pura juntamente

La caridad ardiente:

Para esto jó ninfa del castalio coro!

Tu vor, tu metro, tu favor imploro.

(...)

$Y$ al verlo desplomarse al hondo abismo

Volvi de mi letargo.

$Y$ entonces conocí que todo el sueño

Era un vivo diseño

Del Cementerio abierto en aquel día

Salud y gloria de la patria mía ${ }^{30}$.

Por otra parte, la influencia del Cementerio de Espada se evidencia en otras obras de la arquitectura funeraria cubana construidas durante la primera mitad del siglo XIX. Tal es el caso del Cementerio municipal de Reina, en la provincia de Cienfuegos, inaugurado en junio de 1839, a tres kilómetros de la actual ciudad, que fue declarado Monumento Nacional por la Comisión Nacional de Monumentos, el treinta de enero de 1990. Este campo santo inspirado en el de Espada, con sus pilastras toscanas en la fachada, su pequeño frontón y su simetría que conduce la visual hacia la capilla -de marcada filiación clásica-, localizada en el fondo del recinto, se inserta en la corriente neoclásica imperante en la época. Su forma de enterramiento con tres hileras de nichos que conforman las paredes de su primer patio, constituye en Cuba la única representante de esta tipología, que ha sobrevivido al inexorable paso del tiempo.

Asimismo, el Cementerio de Espada constituyó el antecedente inmediato para el origen de la Necrópolis de Colón, una de las obras más destacadas del arte funerario católico en América, que constituyó un verdadero impulso para la arquitectura y la escultura cubanas de finales del siglo XIX y la primera mitad del XX, con el desarrollo de panteones y monumentos 
funerarios de gran importancia, realizados en muchos casos por artistas de trascendencia internacional ${ }^{31}$. La Necrópolis de Colón, declarada Monumento Nacional en 1987, refleja a través del patrimonio artístico que atesora, la historia de más de un siglo de construcciones funerarias en Cuba. La enorme cantidad de obras de arte, la multiplicidad de estilos y la riqueza de los materiales y técnicas empleadas, se constituyen en expresión de los valores éticos, históricos y estéticos de este relevante paisaje cultural.

El planteamiento del antiguo Cementerio General con la reiteración, repetitiva hasta la saciedad, del sistema de galerías de nichos, con ese implícito significado utópico de ciudad igualitaria producto del pensamiento ilustrado, había quedado superado décadas más tarde por una época distinta, con su consiguiente nueva visión del fenómeno de la muerte. La pujante aristocracia criolla, ansiosa por demostrar su hegemonía social y su posición económica, optó por los suntuosos panteones y costosos conjuntos funerarios que se aprecian en el Cementerio de Colón, auténticos símbolos parlantes de un status, de su riqueza y poder.

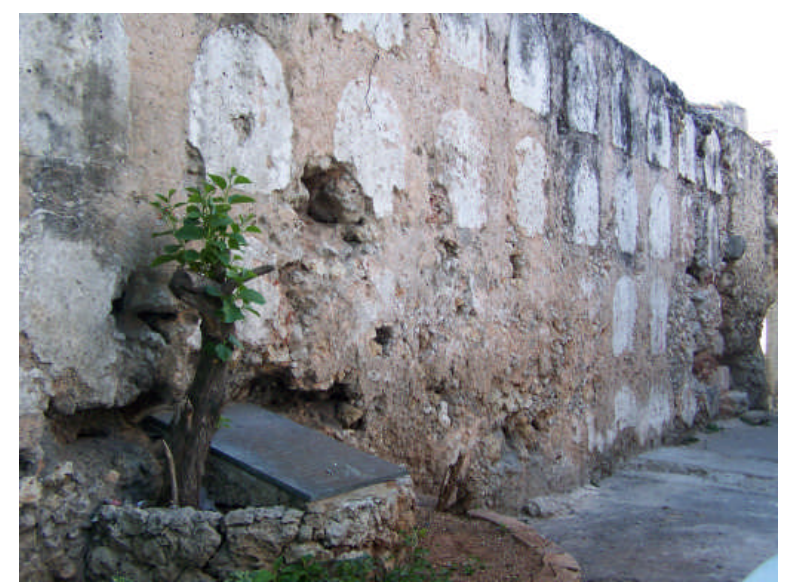

Fig. IV. Fragmento del muro de nichos perteneciente al Cementerio General. (Calles Aramburu y Vapor, Ciudad de La Habana).

No obstante, una pared con unos pocos nichos y tapas del antiguo recinto funerario de Espada subsisten en los términos de la calle Aramburu a la altura de la calle Vapor (Fig. IV), recordando el espacio en que estuvo ubicada esta extinta ciudad de los muertos, resultado de las reformas ilustradas de principios del siglo XIX que, como hemos demostrado, constituyó un ejemplo temprano del neoclasicismo en la arquitectura cubana. 


\section{Notas}

${ }^{1}$ THOMAS, H.: "La colonia española de Cuba". En Historia del Caribe. Editorial Crítica. Barcelona, 2001, pág. 42.

${ }^{2}$ En este sentido, vid. ARUCA ALONSO, L.: "Una nueva visión del Caribe insular. La Real Comisión de Guantánamo (1796-1808). Ilustración y avances en la Isla de Cuba”. En Boletín del Archivo General de la Nación (Santo Domingo). N 121 (2008), págs. 339-364.

${ }^{3}$ El gobierno en la isla de Cuba del capitán general y gobernador Salvador de Muro y Salazar, segundo marqués de Someruelos, se extendió entre 1799 y 1812 -el más prolongado del siglo XIX- y se destacó por un perceptible interés por mejorar las, por entonces, pésimas condiciones culturales e higiénico-sanitarias de la población, dentro de postulados ilustrados. En este sentido, vid. VÁZQUEZ CIENFUEGOS, S.: Tan dificiles tiempos para Cuba. El gobierno del marqués de Someruelos (1799-1812). Universidad de Sevilla. Sevilla, 2008 y VÁZQUEZ CIENFUEGOS, S. y AMORES CARREDANO, J. B.: "La biblioteca del marqués de Someruelos, Gobernador de Cuba (1799-1812)". En Ibero-americana Pragensia-Supplementum (Praga). N 19 (2007), págs. 157-173.

${ }^{4}$ Se refiere al primer hospital que tuvo la villa, creado con limosnas, destinado a atender a los pobres vecinos enfermos y a los forasteros carentes de recursos. Inicialmente se llamó "San Felipe y Santiago" y más tarde "San Juan de Dios". En 1857 este hospital fue declarado de beneficencia pública. En este sentido, vid. TORRE, J. M.: Lo que fuimos y lo que somos o La Habana antigua y moderna. Imprenta de Spencer. La Habana, 1857.

${ }^{5}$ Constituye una de las grandes obras de beneficencia pública que impulsara en La Habana, por suscripción voluntaria, Francisco Dionisio Vives y Planes, capitán general y gobernador de la isla de Cuba entre 1823 y 1832, primero que ejerció el poder en la isla bajo facultades omnímodas. El uno de septiembre de 1828 quedó oficialmente inaugurado este asilo destinado exclusivamente a hombres, situado en la calle de San Lázaro, en unos solares que habían sido empleados para enterrar a los individuos fallecidos en el antiguo Hospital de San Juan de Dios. Hasta ese momento, los enfermos eran alojados en la Casa de Maternidad. Funcionó hasta 1860 en que fueron trasladados a una nueva casa construida a diez kilómetros de la capital, en el llamado "Potrero Ferro", denominado popularmente como "Mazorra".

${ }^{6}$ Era un hospital de leprosos. El nueve de julio de 1714, el Ayuntamiento de La Habana obtuvo una real licencia para fundar un hospital de leprosos. Laureano José de Torres Ayala y Quadros Castellanos (1645-1722), primer marqués de Casa Torres, coronel de los Reales Ejércitos, gobernador y capitán general de la isla de Cuba desde 1708 hasta 1711 y, en segundo mandado, desde 1813 hasta 1816, apadrinó este proyecto con interés. Después de reunir cuantiosos donativos, inició las obras del Hospital de San Lázaro y de su templo, en unos solares situados en la calle Marina esquina a San Lázaro, donde la brisa marítima aparta de la atmósfera de la capital las miasmas de esa dolencia contagiosa. El protomédico, Francisco Teneza y Rubira amplió los terrenos destinados al hospital, donando a tal efecto las parcelas colindantes de su huerta. Estaba a cargo de las hermanas de San Vicente de la Ca- 
ridad. En este sentido, vid. SANTA CRUZ Y MALLÉN, F. X.: "Del Pasado-Por el Conde San Juan de Jaruco. El Hospital de San Lázaro de La Habana". En Diario de la Marina (La Habana). 23-marzo-1947.

${ }^{7}$ Sobre este particular, vid. ROSAÍN Y LUBÍAN, D.: Necrópolis de La Habana Historia de los cementerios de esta ciudad. Imprenta El Trabajo. La Habana, 1875, pág. 13 y MARTÍNEZ MARTÍNEZ, E.: Sucinta descripción de los cementerios de la antigüedad, primitivos de La Habana y el de Cristóbal Colón. Ucar García. La Habana, 1928, págs. 22-23.

${ }^{8}$ A.H.N.C. (Archivo Histórico Nacional de Cuba). (En lo sucesivo aparecerá con las iniciales que acabamos de indicar): Gobierno Superior Civil. Legajo: 89, 1948.

${ }^{9}$ En este sentido, vid. GLANCEY, J. y CUSSANS, T.: Arquitectura. Los edificios más sensacionales del mundo. Espasa-Calpe. Madrid, 2007, págs. 368-369. RODRÍGUEZ LLERA, R.: Breve Historia de la Arquitectura. Editorial Libsa. Madrid, 2006, págs. 173-174 y TRACHTENBERG, M. y HYMAN, I.: Arquitectura de la Prehistoria a la Modernidad. Ediciones Akal. Madrid, 1990, pág. 547.

${ }^{10}$ El Coliseo de las comedias fue sometido a una ampliación en 1846, cuando se renovó la piedra de sillería de la fachada principal y de la lateral que miraba a la bahía de La Habana. Terminado el edificio, en espera de una compañía italiana para inaugurarlo, se produjo el violento huracán del diez de octubre de ese año, sufriendo serios daños, sobre todo la parte antigua de tiempos del gobernador general, marqués de Someruelos, hasta el extremo de que fue abandonado. Posteriormente fue vendido por el Estado y en su lugar se levantó el Hotel de Luz.

${ }^{11}$ WEISS, J. E.: La arquitectura colonial cubana. Siglos XVI al XIX. Instituto Cubano del Libro. Agencia Española de Cooperación Internacional. Consejería de Obras Públicas y Transportes. La Habana, Sevilla, 1996, págs. 274-275.

${ }^{12}$ Sobre este particular, vid. GARCÍA MENOCAL, N. "Etienne-Sulpice Hallet and the Espada Cemetery: A Note". En The Journal of Decorative and Propaganda Arts. Vol. 22. Cuba Theme Issue (1996).

${ }^{13}$ Vid. Papel Periódico de La Habana (La Habana), 9-febrero-1804, pág. 5.

${ }^{14}$ A.G.I. (Archivo General de Indias). (En lo sucesivo aparecerá con las iniciales que acabamos de indicar): CUBA. Legajo: 1717. Se menciona al arquitecto Hallet en documento de veintisiete de julio de 1804 y la existencia de un plan proyectado para el Cementerio General de la capital cubana, con una pared divisoria que establecía tramos específicos para sepultar los cadáveres de personas blancas y de color.

${ }^{15}$ Del análisis del reducido número de imágenes que han llegado hasta nosotros de este recinto funerario se concluye que sólo el ala principal tenía estructura porticada, ya que, a juzgar por varias fotografías, el resto de los flancos estaba configurado por hileras de nichos de cuatro alturas, cubiertos por un tejadillo a doble vertiente de poca inclinación. Estos nichos, como se verá más adelante, fueron construidos en 1845, en cumplimiento de la Real Orden de dos de julio de 1844. Un año más tarde se colocó una lápida que expresaba: "Bajo 
los auspicios del Ecmo. Sr. Gob. Civil Cap. Gral. Vice R. Patrono D. Leopoldo O’Donnell, se dio principio a la construcción de nichos en este sitio".

${ }^{16}$ En este sentido, vid. BARRIO LOZA, J. A.: "Los cementerios neoclásicos porticados en el País Vasco: el caso de Vizcaya”. En Una arquitectura para la Muerte. Actas I Encuentro Internacional sobre los Cementerios Contemporáneos (1991). Consejería de Obras Públicas y Transportes. Sevilla, 1993, págs. 291- 295.

${ }^{17}$ Para la reconstrucción espacial del lugar, resulta fundamental la consulta de tres valiosos textos. En este sentido, vid. ROMAY CHACÓN, T.: Descripción del Cementerio General de La Havana. Imprenta Episcopal de Don Estevan Joseph Boloña. La Habana, 1806. (Se localiza en A.G.I.: SANTO_DOMINGO, 2258). ANDUEZA, J. M.: "Habana. El Cementerio". En Semanario Pintoresco Español (Madrid). Tomo II. N 14 (1851), págs. 105-107 y SANTA CRUZ Y MALLÉN, F. X.: "Del Pasado-Por el Conde San Juan de Jaruco. Sobre el Tema de los Cementerios". En Diario de la Marina (La Habana), 15-junio-1947. Tomándolos como punto de partida hemos realizado una síntesis para aportar una descripción lo más próxima al aspecto original del recinto funerario.

${ }^{18}$ Vid. GORDON Y DE ACOSTA, A. M.: Datos históricos acerca de los cementerios de la Ciudad de La Habana. Imprenta de J. Buquet. La Habana, 1901, pág. 13.

19 A.H.N.C.: Gobierno General. Nº de orden: 15972. Legajo: 332, 1944-1946. (Contiene la solicitud para el establecimiento de nichos en el Cementerio General, como los que existen en el Cementerio de la Sacramental de San Isidro de Madrid) y A.H.N.C.: Gobierno General. $\mathrm{N}^{\circ}$ de orden: 15225. Legajo: 314, 1847-1848. (Este expediente confirma la solicitud referente a la reforma del Cementerio General y el deseo de que se repita, en la medida de lo posible, la estructura del campo santo madrileño).

${ }^{20}$ Puede traducirse como: Ahora aqui duermen en el polvo, Job VI.

${ }^{21}$ Ha resucitado según su palabra: Aleluya. Juan VII. Vid. ANDUEZA, J. M.: Op. cit., pág. 106.

${ }^{22}$ Bienaventurados los muertos que de aqui adelante mueren con el Señor. Si, dice el Espiritu, que descansarán de sus trabajos; porque sus obras con ellos siguen. Apocalipsis, XIV, 13. Vid. SANTA CRUZ Y MALLÉN, F. X.: Op. cit., 15-junio-1947.

${ }^{23}$ La cruz de la capilla del Cementerio de Espada logró sobrevivir a su demolición y actualmente la podemos ver en el Cementerio Cristóbal Colón, sobre una sepultura particular perteneciente a la familia Cabaleiro que se encuentra situada en el campo común número veintiséis, entre las calles I y $1^{\text {ra }}$. Cuando se produjo la demolición del Cementerio General en 1908, se trasladaron a la nueva necrópolis habanera los restos humanos y algunos objetos escultóricos valiosos, entre los que se encontraban tapas de los nichos y la cruz de la capilla.

${ }^{24}$ GARCÍA DE CORONADO, D.: Cementerio de La Habana. Apuntes de su fundación. La Propaganda Literaria. La Habana. 1888, pág. 13.

${ }^{25}$ ROSAÍN Y LUBÍAN, D.: Op. cit., pág. 16. 
${ }^{26}$ WURDEMANN, J. G.: Notas sobre Cuba. Colección Viajeros. Editorial de Ciencias Sociales. La Habana, 1989, pág. 38.

${ }^{27}$ Levantaos muertos y venid a Juicio. Porque sonará la trompeta, lo dice el apóstol San Pablo (1 Corintios, XV, 52): En un momento, en un abrir de ojo, á la final trompeta: porque será tocada la trompeta, y los muertos serán levantados sin corrupción, y nosotros seremos transformados. La trompeta aclara el evangelista San Juan- será la voz de Cristo (Juan, V, 28): No os maravilléis de esto; porque vendrá hora, cuando todos los que están en los sepulcros oirán su voz. Inmediatamente se producirá el hecho colosal de la resurrección de la carne. La frase como tal se atribuye a San Jerónimo (340-420), que fue ordenado sacerdote y se convirtió en consejero del papa San Dámaso, quien le encargó la traducción y revisión de los textos sagrados, circunstancia por la que pasó un tiempo de su vida como eremita en Belén, dedicado al estudio de la Santa Biblia. Por su labor es considerado uno de los doctores de la Iglesia. Para mayor información sobre el tema, vid. GONZÁLEZ ISIDORO, J.: "Aproximación a un estudio iconológico de los ángeles, santos y alegorías en la ciudad de Carmona". En Carel. Carmona, revista de estudios locales (Sevilla). ${ }^{\circ}$ 3 (2005), págs. 1005-1086.

${ }^{28}$ El Templete, ubicado en el lado este de la Plaza de Armas de La Habana Vieja, obedece al esquema de un templo tetrástilo a pequeña escala, de sólidas columnas dóricas coronadas por piñas, basamento ático y en su interior, tres grandes óleos del pintor neoclásico Juan Bautista Vermay, que se instaló en la isla a petición del obispo Espada. El trazado del monumento es obra del coronel de ingenieros Antonio María de la Torre y Cárdenas, nacido en La Habana, hombre de extensa cultura, que ejerció durante dos décadas el cargo de secretario de Gobierno Superior de la isla. En este sentido, vid. SANTA CRUZ Y MALLÉN, F. X.: "Del Pasado-Por el Conde San Juan de Jaruco. El Templete de La Habana". En Diario de la Marina (La Habana), 20-julio-1947. SEGRE, R.: La Plaza de Armas de La Habana. Sinfonía urbana inconclusa. Editorial Letras Cubanas. La Habana, 1992, págs. 14-21 y WEISS, J. E.: Op. cit., pág. 387.

${ }^{29}$ Por solo citar algunos ejemplos: la casa del marqués de la Real Proclamación (Luz esquina a Cuba), la casa de José Ricardo O’Farril (Cuba esquina Chacón), la quinta del conde de Santovenia (el Cerro), quinta del marqués de Pinar del Río (el Cerro), la casa del González Curquejo (Línea esquina a B), el edificio Balaguer (esquina de Monserrate y Ánimas) y el Palacio de la marquesa de Villalba (Monserrate entre Dragones y Monte).

${ }^{30}$ ZEQUEIRA Y ARANGO, M.: "El Cementerio". En Poesías del Coronel D. Manuel de Sequeira y Arango. Imprenta del Gobierno y Capitanía General. La Habana, 1852, págs. 57-63.

${ }^{31}$ Sobre este particular, vid. LAGUNA ENRIQUE, M. E.: La obra de los arquitectos y escultores españoles en el Cementerio de Colón de La Habana. Universidad de Salamanca. Salamanca, 2009 (Trabajo de Grado). 